\title{
An ant-plant by-product mutualism is robust to selective logging of rain forest and conversion to oil palm plantation
}

\author{
Tom M. Fayle • David P. Edwards • William A. Foster • \\ Kalsum M. Yusah • Edgar C. Turner
}

Received: 28 July 2014 / Accepted: 15 December 2014 / Published online: 10 January 2015

(c) The Author(s) 2015. This article is published with open access at Springerlink.com

\begin{abstract}
Anthropogenic disturbance and the spread of non-native species disrupt natural communities, but also create novel interactions between species. By-product mutualisms, in which benefits accrue as side effects of partner behaviour or morphology, are often non-specific and hence may persist in novel ecosystems. We tested this hypothesis for a two-way by-product mutualism between epiphytic ferns and their ant inhabitants in the Bornean rain forest, in which ants gain housing in root-masses while ferns gain protection from herbivores. Specifically, we assessed how the specificity (overlap between fern and ground-dwelling ants) and the benefits of this interaction are altered by selective logging and conversion to an oil palm plantation habitat. We found that despite the high
\end{abstract}

Communicated by Julia Koricheva.

Electronic supplementary material The online version of this article (doi:10.1007/s00442-014-3208-z) contains supplementary material, which is available to authorized users.

\section{T. M. Fayle ( $\varangle)$}

Faculty of Science, University of South Bohemia, Branišovská 31, 37005 České Budějovice, Czech Republic

e-mail: tmfayle@gmail.com

T. M. Fayle $\cdot$ K. M. Yusah

Institute of Entomology, Biology Centre of the Academy of Sciences Czech Republic, Branišovská 31, 37005 České

Budějovice, Czech Republic

T. M. Fayle

Forest Ecology and Conservation Group, Imperial College London, Silwood Park Campus, Buckhurst Road, Ascot, Berkshire SL5 7PY, UK

D. P. Edwards

Department of Animal and Plant Sciences, University

of Sheffield, Western Bank, Sheffield S10 2TN, UK turnover of ant species, ant protection against herbivores persisted in modified habitats. However, in ferns growing in the oil palm plantation, ant occupancy, abundance and species richness declined, potentially due to the harsher microclimate. The specificity of the fern-ant interactions was also lower in the oil palm plantation habitat than in the forest habitats. We found no correlations between colony size and fern size in modified habitats, and hence no evidence for partner fidelity feedbacks, in which ants are incentivised to protect fern hosts. Per species, non-native ant species in the oil palm plantation habitat $(18 \%$ of occurrences) were as important as native ones in terms of fern protection and contributed to an increase in ant abundance and species richness with fern size. We conclude that this by-product mutualism persists in logged forest and oil palm plantation habitats, with no detectable shift in partner benefits. Such persistence of generalist interactions in novel ecosystems may be important for driving ecosystem functioning.

\section{P. Edwards}

School of Marine and Tropical Biology, Centre for Tropical Environmental and Sustainability Science (TESS), James Cook University, Cairns, QLD, Australia

W. A. Foster - E. C. Turner

Insect Ecology Group, University Museum of Zoology

Cambridge, Downing Street, Cambridge CB2 3EJ, UK

\section{K. M. Yusah}

Institute for Tropical Biology and Conservation, Universiti Malaysia Sabah, Jalan UMS, 88400 Kota Kinabalu, Sabah, Malaysia 
Keywords Bird's nest fern · Formicidae $\cdot$ Malaysian Borneo $\cdot$ Oil palm $\cdot$ Rain forest

\section{Introduction}

When humans severely alter the environment, ecologically stable, novel ecosystems can be created (Hobbs et al. 2009). These ecosystems are characterised by the extinction of some species (Tilman et al. 2001), invasion by others (Mack et al. 2000), and shifts in the abiotic environment (Ewers and Banks-Leite 2013). As a consequence, the network of interactions between species can be significantly altered (Tylianakis et al. 2010), with the loss of individual species leading either to co-extinctions of species reliant on each other (Koh et al. 2004) or increases in abundance of species whose competitors or natural enemies disappear (Ritchie and Johnson 2009). These processes are expected to change the adaptive landscape in newly formed ecosystems, with shifts in the costs and benefits of associations between specific partner species (Aslan et al. 2013).

Mutualistic interactions between species are widespread in both natural and novel ecosystems. Some mutualisms are highly specific, with each partner having evolved to invest reciprocally in the other's fitness (Foster and Wenseleers 2006). However, it is now clear that generalist mutualisms, including those defined as "by-product mutualisms" (Leimar and Connor 2003), are also widespread (Bronstein et al. 2006). A by-product mutualism occurs when each of the species involved acts to optimise its own fitness, and the by-product of doing this is an increase in the fitness of the partner. Critically, there is no evolved investment in partner fitness, and these relationships tend to remain diffuse and non-specific (Leimar and Connor 2003). By-product mutualisms are expected to persist in novel ecosystems in which many native species are no longer present because the species involved are generalists and not reliant on a single partner. Hence, the interaction could persist under two scenarios: (1) a subset of the remaining partners continue to interact, or (2) invading non-natives fill the roles vacated by locally extinct partners.

Globally, many species with no recent shared evolutionary history are being brought together by the creation of novel ecosystems through anthropogenic habitat degradation and the transport of species around the world. Across the tropics, a major driver of such changes is selective logging of forests (Edwards et al. 2014b) and subsequent conversion to agriculture (Tilman et al. 2001). Selectively logged forest often retains similar numbers of species to primary forest across a range of taxa (Gibson et al. 2011), but has altered species composition (Edwards et al. 2014a). Conversion to agriculture typically has more extreme impacts (Edwards et al. 2014a; Gibson et al. 2011), with loss of forest species and invasion by non-natives (Mack et al. 2000)-and hence increased likelihood of the formation of novel species interactions. Although these nonnative species are often considered in a negative context, they have the potential to be functionally important in novel ecosystems (Davis et al. 2011).

Mutualistic interactions between ants and plants are widespread, with plants trading housing or food for antprovided protection from herbivores, seed dispersal or food collection (Bronstein et al. 2006). Mutualistic ant-plant networks are known to be fairly robust to habitat degradation (Bruna et al. 2005; Passmore et al. 2012), but the effects of degradation on the benefits for partners, at least for mutualisms where plants provide housing, are less wellknown (Wetterer 1997). In the study reported here, we focussed on an ant-epiphyte interaction that persists across a disturbance gradient from primary forest to selectively logged forest and oil palm agriculture (Fayle et al. 2010; Turner and Foster 2009) in Malaysian Borneo, Southeast Asia. This region is a biodiversity hotspot (Myers 2000), which is suffering from an accelerating rate of deforestation (Hansen et al. 2013), driven mainly by expansion of oil palm plantations (Koh and Wilcove 2008). Bird's nest ferns (Asplenium spp.) are litter-trapping epiphytes that form a two-way by-product mutualism in primary forest with their ant inhabitants, with ferns providing multiple colonies of ants with a nest site in their root mass and the ants protecting ferns from herbivores (Fayle et al. 2012). However, since the root mass is not enclosed or partitioned, being adapted for the capture and breakdown of leaf litter, ferns are unable to direct housing benefits to more beneficial ant partners. Larger ferns thus support more ant colonies of different species rather than larger colonies of cooperating species, which in turn means that ant species that are more beneficial are unlikely to benefit greatly from helping ferns to grow (i.e. they are less likely to receive partner fidelity feedbacks) (Fayle et al. 2012). This is in contrast to plants that house ant partners in adapted, enclosed structures (termed domatia) and are, consequently, able to direct benefits by rewarding or punishing specific ant colonies depending on their behaviour (Edwards et al. 2006).

Logging and conversion to oil palm plantation might affect the bird's nest fern-ant interaction in a number of ways. Increasing homogenisation of ant faunas with disturbance, in particular compression of communities in response to vertical collapse of microclimate regimes (Fayle et al. 2009; Scheffers et al. 2013), is expected to reduce the specificity of the interaction (but see Beaulieu et al. 2010). Since bird's nest ferns support substantial amounts of leaf litter, we would expect this collapse to result in increasing similarity between fern-dwelling ant communities and ant communities inhabiting leaf litter on the forest floor. Predation rates by ants are known to 

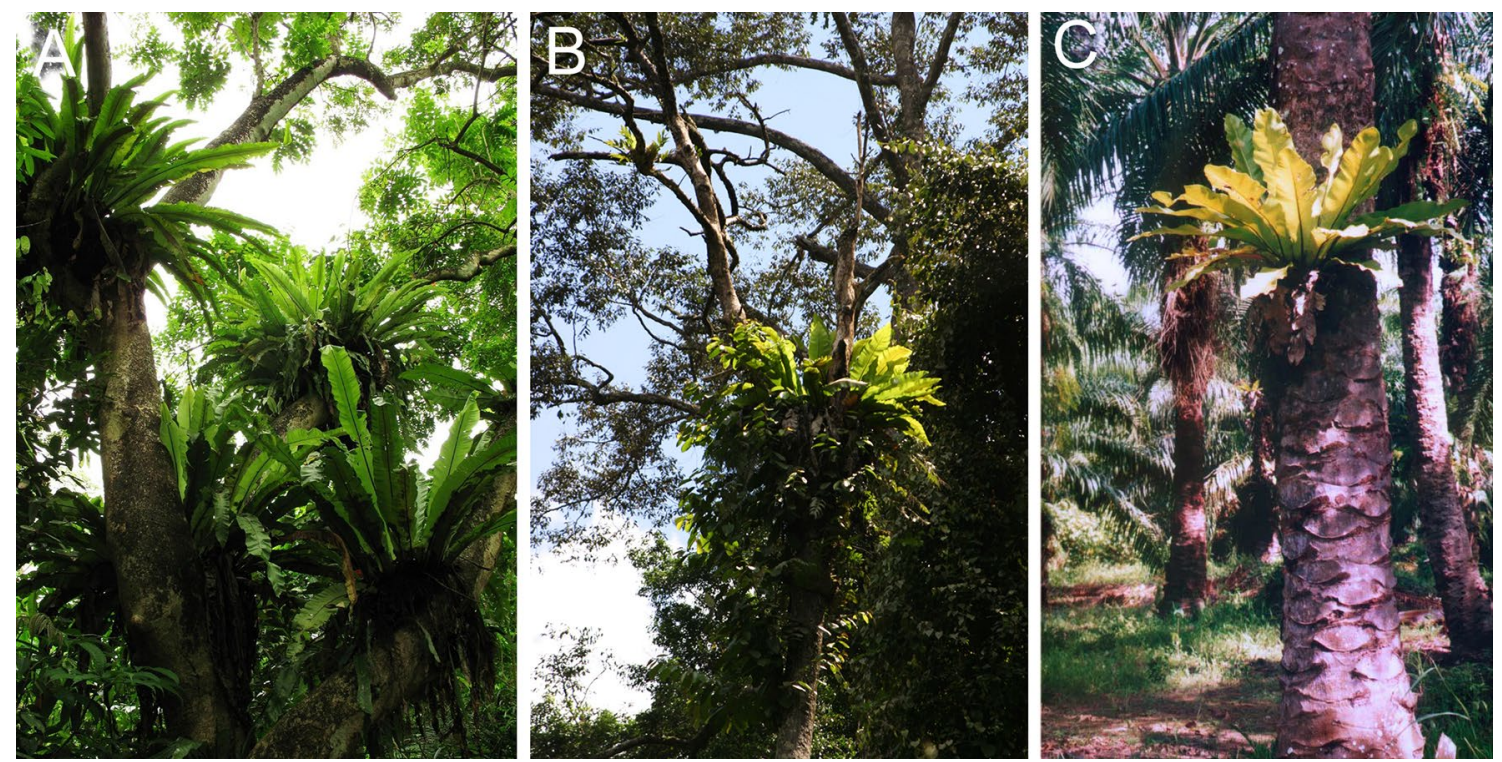

Fig. 1 Bird's nest ferns (Asplenium spp.) are abundant in habitats across a gradient of habitat modification in Southeast Asia, from primary forest (a) to logged forest (b) to oil palm plantation (c). Two closely related bird's nest fern species co-exist in primary forest (their distribution is unknown in logged forest and oil palm plantation): $A$.

increase with disturbance (Tvardikova and Novotny 2012), and non-native species, which commonly invade disturbed areas, are often better protectors of plants than native species (Ness and Bronstein 2004). The relationship between fern size and the number and size of resident colonies has implications for the benefits to ants to invest in fern growth, and hence on the potential for partner fidelity feedbacks (Weyl et al. 2010). There are two possible disturbancelinked changes to these partner fidelity feedbacks: either resident ants expand colony sizes as fern size increases (and hence reap benefits from investment in fern fitness), or extra living space is co-opted by new ant colonies (and hence residents would not benefit from investment, as is the case in primary forest, see above). Non-native ant species, which can play key roles in mutualisms (Ness and Bronstein 2004), occur in bird's nest ferns in oil palm plantations (Fayle et al. 2010), but their role in this by-product mutualism is not known. A species pool of functionally equivalent fern-dwelling ant species (both natives and non-natives), including those robust to habitat disturbance, would allow persistence of the by-product mutualism in this altered habitat.

We used the ant-fern model system to investigate whether a non-specific, two-way by-product mutualism can survive selective logging and conversion to oil palm plantation, with quantification of the relative roles of native and non-native species in driving this interaction in altered habitats. In this context, we tested three hypotheses: (1) that the degree of specificity of the ant-fern interaction, as phyllitidis and A. nidus (Fayle et al. 2009), with A. phyllitidis being by far the more abundant at the heights surveyed in this study. The two species are morphologically very similar and often only distinguishable using molecular characters

measured by the overlap between fern-dwelling ants and the pool of potential colonists from leaf litter on the forest floor, will decrease with disturbance; (2) that the degree of protection from herbivory provided by the ants to their host ferns will increase with disturbance, since ant predation rates are known to be higher in more disturbed areas (Tvardikova and Novotny 2012); (3) that the potential for partner fidelity feedback between fern size and ant colony size will be unaffected by disturbance, since ant housing is not enclosed or partitioned in modified habitats, thereby limiting the degree of investment in fern growth by ants.

\section{Materials and methods}

Study sites

Bird's nest ferns and ants were collected in May and June 2002 in three habitats in Sabah, Malaysian Borneo (Fig. 1): primary forest within the Danum Valley Conservation Area $\left(117^{\circ} 48^{\prime} \mathrm{E}, 4^{\circ} 58^{\prime} \mathrm{N}, \mathrm{m}\right.$ a.s.l. $\left.170 \mathrm{~m}\right)$, nearby forest that had been selectively logged once in 1988 , with $113 \mathrm{~m}^{3} / \mathrm{ha}$ of timber removed (Fisher et al. 2011) $\left(117^{\circ} 50^{\prime} \mathrm{E}, 4^{\circ} 57^{\prime} \mathrm{N}, \mathrm{m}\right.$ a.s.l. $170 \mathrm{~m})$ and mature oil palm plantation $(143$ palms/ ha), planted $14-18$ years previously $\left[118^{\circ} 35^{\prime} \mathrm{E}, 5^{\circ} 01^{\prime} \mathrm{N}\right.$, m a.s.l. $150 \mathrm{~m}$; Electronic Supplementary Material (ESM) Fig. S1]. The climate of the area is aseasonal, although with occasional droughts (Walsh and Newbery 1999), none of which coincided with our sampling period. 


\section{Ant-fern censuses}

Twenty ferns were censused in each habitat (total $N=60$ ) using a size-based random-stratified sampling scheme (frond tip to tip diameter: $0-50 \mathrm{~cm}, 6$ ferns; $50-100 \mathrm{~cm}, 8$ ferns; $>100 \mathrm{~cm}, 6$ ferns). This stratification was done to ensure maximal power to detect relationships between fern size, and ant community and colony responses in analyses of partner fidelity feedback. Each fern was collected into a plastic bag using ladders and the single rope technique, then weighed, dissected, and placed into a Winkler-type extractor for 3 days. Fern material was then searched by hand for remaining ants, dried to constant mass at $60{ }^{\circ} \mathrm{C}$, and weighed again. Ants were identified to the genus level (Fayle et al. 2014) and then sorted to species/morphospecies using published keys (Agosti 1992; Bolton 1977; Kohout 2006; Shattuck 2008; Wang 2003) and the antweb. net online image database (Pfeiffer 2013). The presence of workers was used as an indication of the presence of a colony (191 occurrences of 87 species in total across all 3 habitats; ESM Table S1). Vouchers are deposited at the University Museum of Zoology, Cambridge, UK.

\section{Measuring mutualism specificity}

Habitat modification could alter both the available ant partners and the proportions of those species residing in the ferns. We therefore surveyed leaf litter ant communities at the time of fern collection, collecting four $1-\mathrm{m}^{2}$ litter samples as close to the focal tree as possible on bearings of $0^{\circ}$, $90^{\circ}, 180^{\circ}$ and $270^{\circ}$; these were processed in the same way as the fern samples. Compared with other microhabitats, ground-based leaf litter ant communities are likely to be most similar to the ant communities in the ferns, since both microhabitats comprise decomposing leaf litter. To assess overlap in ant communities between ferns and litter on the ground, we used the Chao-Jaccard index, which corrects for undersampling, with 200 bootstrapped replications to generate standard errors (Colwell 2009). We also assessed changes in the occupancy rates of ferns (binary factor) due to logging and conversion to oil palm plantation, using an ordered contingency table (lbl_test function in R package coin; Hothorn et al. 2008), on the assumption that changes would be monotonic.

\section{Assessing protection of ferns by ants}

For each fern, we measured the total frond area and the area removed by herbivores and calculated the proportion of herbivory (following Fayle et al. 2012). We then used beta regression with a logit link function, a standard method for modelling proportions (Cribari-Neto and Zeileis 2010), to model the proportion of herbivory as a function of the number of ant colonies, total ant abundance (summed across all colonies in the fern), fern dry mass (since older, larger ferns were likely to have accumulated more herbivory), proportion of fern dry mass as leaf litter, fern core moisture content (grams moisture per gram dry mass fern) and habitat.

Ant exclusions were conducted in 2003 to verify any correlational patterns. On 20 additional ferns in each habitat (diameter 50-180 cm, height above ground level 0.8$3.3 \mathrm{~m}$ ), we selected two fronds of similar size with minimal herbivory and assigned these to control and ant exclusion treatments at random. The ant exclusion frond base was covered with tanglefoot glue, while control fronds were left untreated. Any twigs or leaves in contact with the control or exclusion treatment fronds that would allow access by ants to the fronds were removed. Note that this approach is conservative in that non-flying herbivores were unable to access treatment (exclusion) fronds; hence our experiment assessed only the impacts of ant patrols on flying, ballooning, and jumping herbivores, as well as on any larvae developing from eggs laid by these species. After 2 months, the fronds were collected and the proportional area of herbivory measured and analysed using a generalised additive model (GAM) with beta error structure and a logit link (Stasinopoulos and Rigby 2007). We looked initially for an interaction between the effect of the experimental treatment and the effect of habitat, since this would indicate that ant protection of ferns was affected by habitat modification.

Investigating partner fidelity feedbacks

We first analysed relationships between fern size and colony size for common ant species (those present in $\geq 5$ ferns in each habitat), applying a sequential Bonferroni correction for multiple comparisons across species (Sokal and Rohlf 1995). We then analysed the overall relationship between fern size and total ant abundance, and between fern size and number of colonies. Linear models were used, and fern mass and ant abundance were log transformed for all analyses.

Exploring the role of non-native ant species in modified habitats

Since non-native ant species are often widespread and ecologically important in modified habitats, we expected these to affect interaction specificity, ant protection and partner fidelity feedbacks. We defined non-natives as those categorised as invasive, alien or tramp by Pfeiffer et al. (2008). Excluding non-native species from our data, we repeated three of our analyses (final models only) assessing: (1) fern and litter community similarity; (2) herbivory rates and ant occupancy; (3) fern size and ant abundance/ 


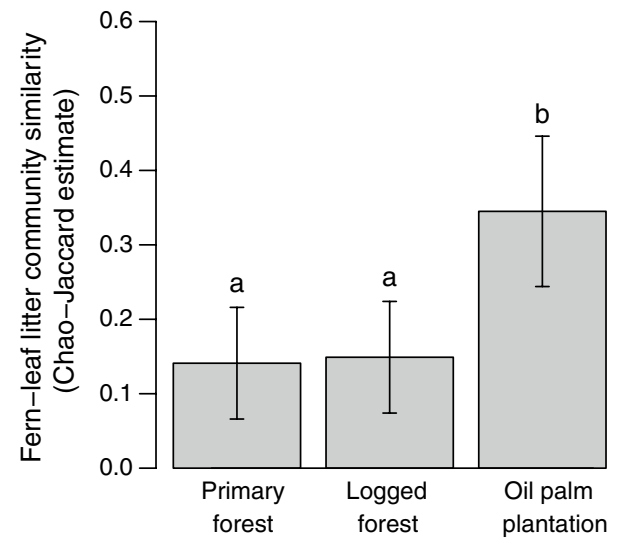

Fig. 2 Similarity in species composition between fern-dwelling ant communities and those from ground leaf litter was greater in the oil palm habitat than in either the primary or logged forest, which did not differ from each other. Bars show mean incidence-based Chao-Jaccard similarities \pm standard deviation (SD). Different letters denote significant differences between groups based on $t$ tests on bootstrapped data $(N=200$ replications $)$

species richness. To test whether non-native species differed in their effects from the rest of the community, we used null models in which we ran each of these analyses a further 5,000 times with the same number of species (other than non-natives) removed at random. This methodology allowed us to test whether the observed analytical outputs were significantly different from what would be expected if non-native ant species were functionally indistinguishable from the rest of the ant community. $P$ values were generated by comparing the observed output value to null distributions. These analyses were conducted only in oil palm plantation, since non-native species are not abundant elsewhere (primary forest 0/61 ant colonies; logged forest: 2/62 ant colonies). It should be noted that since a number of less well-known non-native species may not have been identified, our analyses represent a minimum (and conservative) estimate of the importance of non-native ants.

\section{Results}

Mutualism specificity and habitat modification

Mutualism specificity was altered by habitat modification (Fig. 2). The degree of similarity between fern and litter communities was low in both primary and logged forest, and similarity did not differ significantly between these habitats ( $t$ test: $N=20, t=0.3, P=0.737$; Fig. 2). However, community similarity between fern and litter ants was significantly higher in oil palm plantation $[t$ tests: primary forest (primary)-oil palm plantation (oil palm): $N=20$, $t=7.3, P<0.001 ;$ logged forest (logged)-oil palm: $N=20, t=7.0, P<0.001]$. The total number of ant species in the ferns was similar across the three habitats (primary: 36; logged: 35; oil palm: 35; ESM Table S1), while fern occupancy rates were reduced with increasing disturbance (primary: $100 \%$; logged: $85 \%$; oil palm: $75 \%$; ordinal contingency test: $\chi^{2}=5.32, N=60, P=0.021$ ). There were relatively few fern-dwelling ant species in common between the habitats (primary-logged forest overlap 11 species; primary-oil palm overlap 2 species; logged-oil palm overlap 6 species). The reader is referred to Fayle et al. (2010) for further description of changes in ant community composition.

Ant protection of ferns and habitat modification

Across all habitats, ferns with more colonies of ants experienced lower levels of herbivory (beta regression: $Z_{5,58}=-2.07, P=0.039$; Fig. 3a), while larger ferns $\left(Z_{5,58}=2.82, P=0.005\right.$; Fig. 3b $)$ and those with more leaf litter $\left(Z_{5,58}=2.04, P=0.042\right.$; Fig. 3c) experienced higher levels of herbivory. There was no effect of habitat, fern core moisture content or ant abundance on herbivory $(P>0.2)$. For a fern of average size (dry mass $249.0 \mathrm{~g}$ ) and with an average proportion of its dry mass as leaf litter (0.167), the predicted leaf area missing through herbivory is $11.9 \%$ for a fern occupied by six ant colonies, increasing to $17.2 \%$ for an uninhabited fern (45\% difference). We found that experimental ant exclusion increased herbivory across all habitats (GAM: $t_{43,74}=2.59, P=0.011$; Fig. $3 \mathrm{~d}$ ), with no differences between habitats in terms of the strength of this effect (primary vs. oil palm: $t_{43,74}=1.60, P=0.119$; logged vs. oil palm: $t_{43,74}=0.37, P=0.710$, primary vs. logged: $\left.t_{43,74}=1.19, P=0.236\right)$ and no significant interaction between habitat type and effect of ant exclusion (all $P>0.05$ ). Ant exclusion increased the leaf area lost to herbivores over a 2-month period from 0.6 to $1.2 \%$ (95\% increase across all habitats).

Partner fidelity feedback and habitat modification

For common ant species ( $\geq 5$ colonies in a habitat), there was no relationship between colony size and fern size, although larger ferns supported higher total abundances of ants (Fig. 4a). However, this relationship was habitat dependent (Linear model; fern size $\times$ habitat interaction: $t_{5,54}=-2.36, P=0.022$ ), with abundance increasing more slowly with fern size in the oil palm plantation than in forest habitats (Fig. 4a). Larger ferns were also inhabited by more species of ant (Linear model: $t_{3,56}=5.60, P<0.001$; Fig. 4b), and ferns in primary forest did not differ from those in logged forest or oil palm plantation in this relationship. In contrast, ferns in logged forest supported more ant 

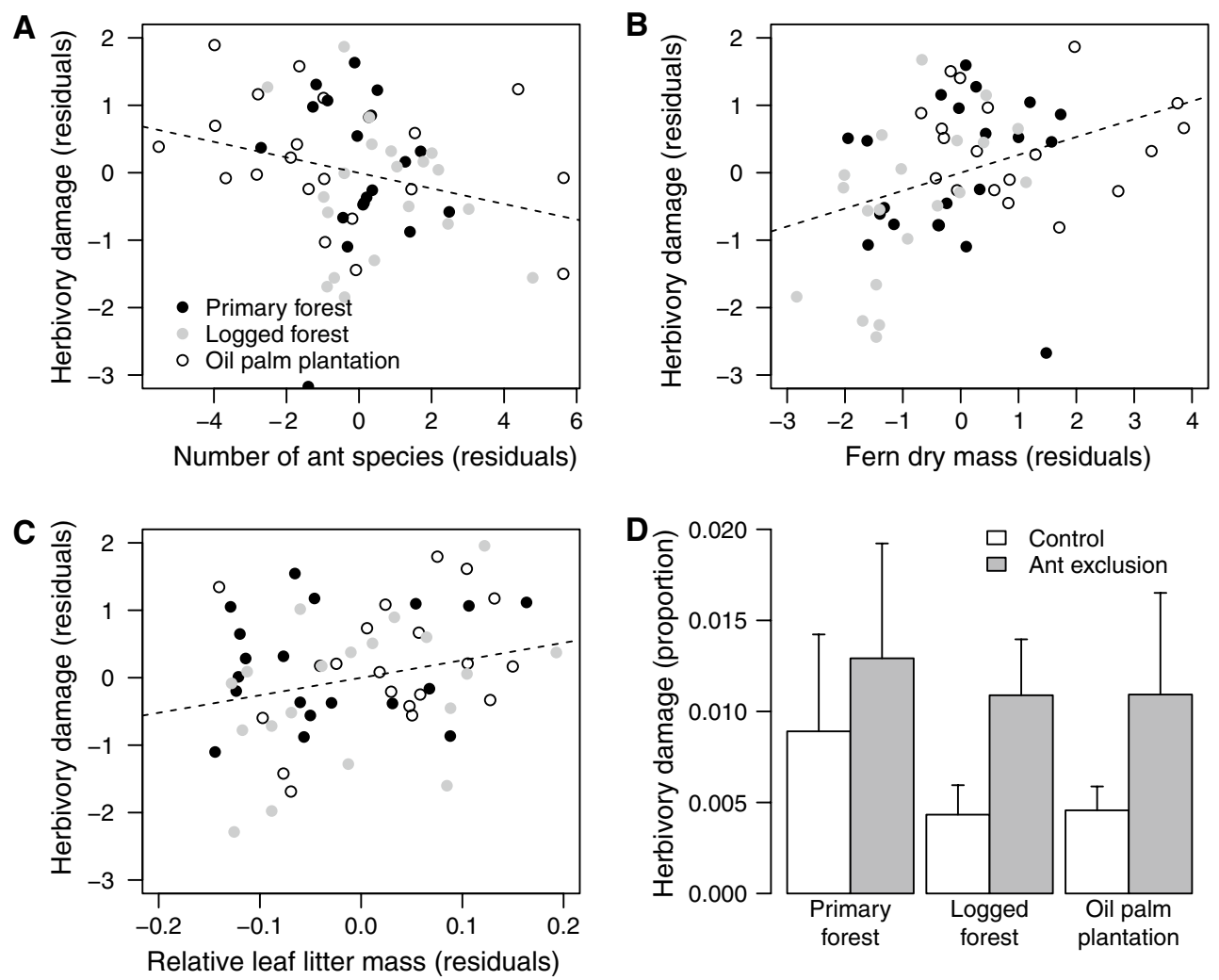

Fig. 3 Herbivory rates were lower in ferns occupied by more colonies of ant (a), higher in larger ferns (b) and higher in ferns with greater accumulations of leaf litter (c). These effects did not differ between habitats. Experimental exclusion of ants resulted in increased rates of herbivory across primary forest, logged forest and oil palm plantation (d), with no differences between habitats in this effect. Note that treatments and controls are paired. Mean proportions

species than ferns in oil palm plantation for a given fern size (primary vs. logged: $t_{3,56}=1.15, P=0.254$, primary vs. oil palm: $t_{3,56}=1.36, P=0.179$; logged vs. oil palm: $\left.t_{3,56}=2.30, P=0.026\right)$. There were no significant firstorder interactions between any of the predictors in analyses of species richness.

The role of non-native ant species in mutualism in oil palm plantation

There was no difference in the degree of similarity between fern-dwelling and litter-dwelling ant communities, or in the relationship between ant species richness and herbivory, when analyses excluding non-native species from the oil palm habitat dataset were carried out (Chao-Jaccard metric: non-natives removed 0.328 , null median 0.364 , $P=0.061$; Fig. 5a; beta regression coefficient: non-natives removed -0.055 , null median $-0.062, P=0.089$; Fig. 5b). However, the relationship between fern size and ant abundance (Linear model coefficient for fern size: non-natives

removed 0.474 , null median $0.542, P=0.006$; Fig. 5c) and that between fern size and number of colonies (Linear model coefficient for fern size: non-natives removed 1.05, null median $1.17, P=0.010$, two tailed test; Fig. $5 \mathrm{~d}$ ) was weaker with non-native species removed than with them present, indicating that non-native species are more important than the rest of the community in contributing to these relationships.

\section{Discussion}

The ongoing anthropogenic modification of global ecosystems is bringing together novel combinations of species (Hobbs et al. 2009). This is expected to cause shifts in the functioning of ecosystems, with associated changes to the costs or benefits of specific interactions. For ants engaged in a by-product mutualism with bird's nest ferns, we found that the interaction persisted following disturbance by selective logging and conversion to oil palm plantation and 

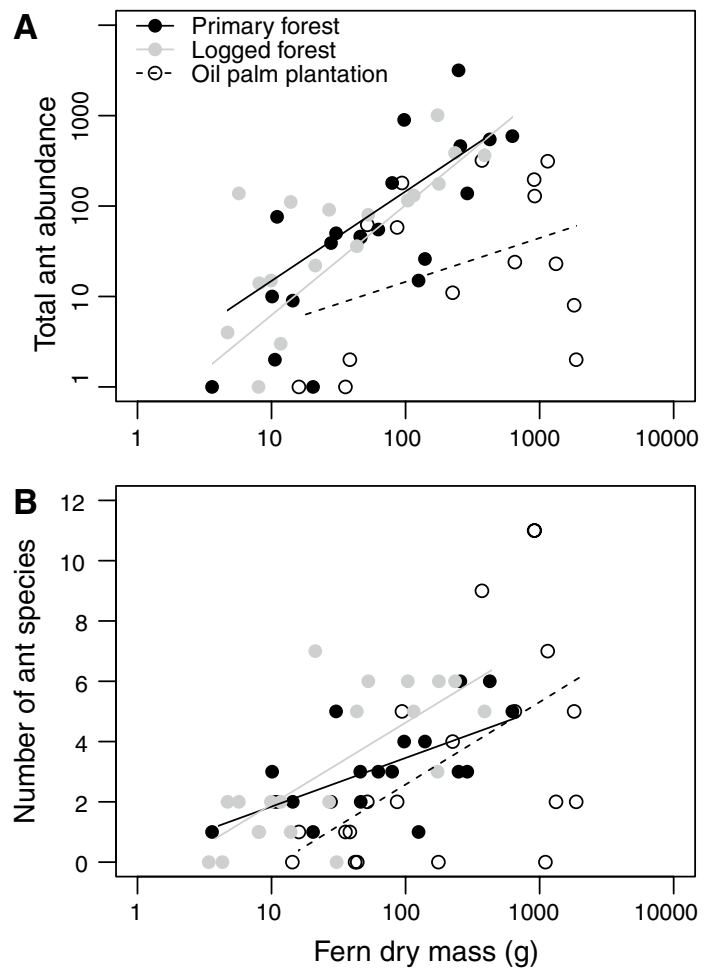

Fig. 4 Total ant abundance (a) and the number of ant species present (b) were greater in larger ferns. For a given size, ferns in oil palm plantation supported lower abundances of ants than ferns in primary or logged forest, and fewer ant species than ferns in logged forest

that ant protection of ferns is maintained, despite a reduction in the mutualism specificity and lower occupancy rates in oil palm ferns. This contrasts with the negative impacts of anthropogenic disturbance observed for a range of other mutualisms (Kiers et al. 2010; Potts et al. 2010).

The persistence of the ant-fern interaction probably relates to the low degree of specificity between ants and bird's nest ferns. In primary forest, at least 71 species of ants inhabit the ferns (survey of 83 ferns; Fayle et al. 2012). Because fern cores are not enclosed or partitioned, they are unable to filter ant partners (e.g. by constraining the shape of a preformed entrance hole; Brouat et al. 2001) or to direct punishments (e.g. by aborting structures supporting cheating colonies; Edwards et al. 2006) as occurs in domatia-provisioning ant-plant mutualisms (those in which plants provide enclosed structures adapted for ant inhabitation). Hence, the non-specific nature of the ant-bird's nest fern by-product mutualism appears to allow the persistence of this relationship even in a novel ecosystem. Indeed, the relationship becomes even less specific in oil palm plantation (Fig. 2), indicating a homogenisation of the fern-dwelling and litter-dwelling ant faunas. We therefore predict that in novel ecosystems generated by significant disturbance, highly specific interactions will be more likely to go extinct
(Koh et al. 2004), with only a core of non-specific interactions (such as by-product mutualisms) remaining. This "skeletonisation" of interaction networks is likely to have consequences for the way that novel ecosystems function and could prove a fruitful direction for further research.

One consequence of the persistence of ant-fern interactions that we noted was the continued protection of ferns from herbivory in disturbed habitats (Fig. 1a, d). Such robustness is presumably driven by foraging of resident ants on vegetation near to their nest for insect prey, with the effect persisting despite lower overall abundances of ants in oil palm plantations (Fig. 4a). One possible explanation is that lower ant abundances are compensated for by increased levels of patrolling, due either to higher temperatures in this habitat (Turner and Foster 2006) or by a combination of species turnover and species-specific differences in patrolling rates (Bruna et al. 2004). Larger ferns exhibited more herbivory, probably because they were older and, consequently, their fronds had been exposed to herbivores for a longer period of time. Ferns with more leaf litter also experienced more herbivory, possibly because a larger volume of leaf litter is likely to buffer microclimate more efficiently (Turner and Foster 2006) and hence act as a refuge for herbivores. The difference in magnitude between observed levels of herbivore damage $(11.9 \%$ for a fern of average size and litter mass) and those found on control ferns $(0.6 \%$ over a 2 -month period) indicates that fronds may be long-lived and, hence, that there may be high costs of damage, particularly early in development. The persistence of ant protection of ferns is likely to reflect the continuing control of herbivores in the wider oil palm landscape (Wielgoss et al. 2014). Therefore, species known to be involved in non-specific interactions in pristine habitats may be the most promising candidates for delivering services in degraded and novel ecosystems. However, in our study, the increased overlap between ground-dwelling and fern-dwelling ant communities indicates that the byproduct mutualism in oil palm is dependent on a larger proportion of species present in the habitat as a whole. This might lead to increased vulnerability of fern protection to ant species extinction.

The overall structure of partner-fidelity feedbacks remained the same in the disturbed habitats, with larger ferns generally supporting more colonies of ants, rather than larger colonies of particular ant species. However, oil palm ferns supported lower overall abundances of ants for a given size (and also fewer colonies) than in logged forest ferns. Furthermore, the proportion of occupied ferns decreased with increasing disturbance. Lower ant occupation of oil palm ferns could be due to a reduction in the volume of ferns suitable for habitation: due to the hotter, drier microclimate in plantations (Foster et al. 2011; Turner and Foster 2006) the root mass dries out more rapidly, 

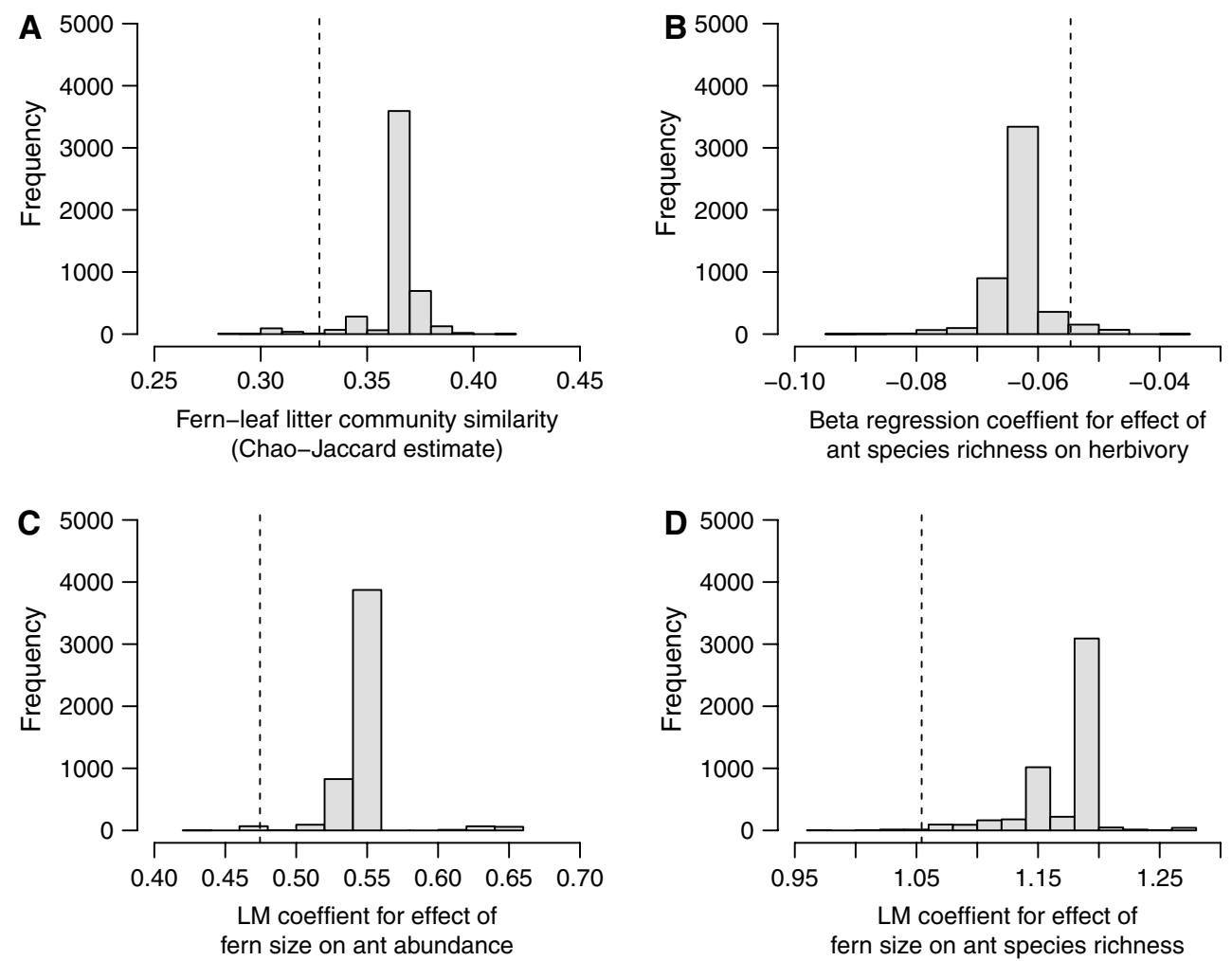

Fig. 5 Exclusion of non-native species from analyses in the oil palm plantation resulted in no difference in similarity between fern and leaf litter ant communities (a), no difference in the correlation between ant species richness and herbivory rates (b), a weaker relationship between ant abundance and fern size (c), and a weaker relationship

potentially leaving only the centre of the fern habitable [fern moisture content: $0.85 \mathrm{~g}$ water/g dry mass in oil palm ferns vs. $1.53 \mathrm{~g} / \mathrm{g}$ in primary and $1.42 \mathrm{~g} / \mathrm{g}$ in logged forest ferms; Fig. ESM S2; see Scheffers et al. (2014) for this effect on frogs]. Despite the lower ant abundance and species richness in oil palm plantation, there was no increase in the proportion of ferns supporting single ant colonies, which would be expected to lead to closer relationships between fern size and ant colony size, and hence for an increase in the potential for partner fidelity feedback creation (primary forest: $4 / 20$ ferns, logged forest: $3 / 20$, oil palm: $3 / 20$ ).

The persistence of by-product mutualism in the highly disturbed oil palm plantation habitat was reliant to some extent on the presence of non-native species. On a per-species basis, these non-native species were more important than the rest of the community in terms of the relationships between fern size and ant abundance, and between fern size and species richness. Non-native species were not significantly different from the rest of the community in terms of their predicted contribution to fern protection. Widespread invasive and tramp species are well documented as disruptors of animal-plant mutualisms (Traveset and Richardson between ant species richness and fern size (d). Vertical lines denote single parameter values derived from removal of all non-native species, histograms plot distributions of parameter values with the same number of randomly selected other species repeatedly removed. $L M$ stands for Linear Model

2006). Conversely, these species are often locally highly abundant (Mack et al. 2000), and hence their potential to function in by-product or generalist mutualisms may be even greater than that of native species (Aizen et al. 2008). Indeed, in oil palm plantations, non-native species are widespread both on the ground and in the canopy (Fayle et al. 2010), with the canopy sometimes supporting even higher densities of non-natives than are found in the ferns (18\% of occurrences in ferns in this study; $46 \%$ of occurrences in the canopy in Pfeiffer et al. 2008).

The high abundance of non-native ants elsewhere in the environment, combined with the non-specific nature of the by-product mutualism, seems to have allowed non-native ants to take the place of some of the rain forest species that were lost when habitats were modified. There could, therefore, be a shift in the selective pressures on the partners involved in this relationship, with a potential for evolutionary changes over longer time periods. However, since the mutualism is a by-product of otherwise adaptive behaviours for both partners, there is probably less potential for such changes than there would be for a more intimate novel relationship. Invasion by non-natives also potentially changes the adaptive landscape for remaining native ant species, 
particularly if non-natives are highly competitive, although this appears not to be the case for ants inhabiting oil palm ferns (Fayle et al. 2013). It should be noted that, in our study, non-native species in oil palm ferns comprised only a minority of the overall species occurrences (18\%), and of the non-native occurrences we observed in ferns, $50 \%$ were of a single species, Monomorium floricola. Hence, the broader impact of non-natives in this system remains unclear.

In conclusion, we have demonstrated that a by-product mutualism persists along a gradient of habitat modification, with no detectable changes in the benefits for the partners. We also found that non-native species may play roles in such generalist mutualisms in highly disturbed habitats. Our results support the notion that management practices should take into account these robust interactions and functions in novel ecosystems and tailor management efforts to support them (Hobbs et al. 2009; Melo et al. 2013). As the footprint of human disturbance continues to expand globally, so the role of novel species and ecosystems will increase. The consequences of this expansion on the linkages that bind together species into communities and the effects of these changes on species' evolutionary trajectories are only just starting to be understood.

Acknowledgments We are grateful to Glen Reynolds and the Royal Society's South East Asia Rainforest Research Programme for logistic support, Arthur Y. Chung and Chey Vun Khen for local assistance and the Economic Planning Unit, Putrajaya, Danum Valley Management Committee, Yayasan Sabah and Sabah Chief Minister's Department for permission to conduct research in Sabah. We would also like to thank three anonymous reviewers for comments that improved this article. TMF and ECT were funded by the Natural Environment Research Council, TMF by Yayasan Sime Darby, the project "Biodiversity of Forest Ecosystems" CZ.1.07/2.3.00/20.0064 co-financed by the European Social Fund and the state budget of the Czech Republic, the Czech Science Foundation (Reg. nos. 14-32302S, 14-04258S) and the Australian Research Council (DP140101541) and ECT by the Isaac Newton Trust, Cambridge and PT Sinar Mas Agro Resources and Technology Tbk. DPE was supported by an Australian Laureate Postdoctoral Fellowship.

Open Access This article is distributed under the terms of the Creative Commons Attribution License which permits any use, distribution, and reproduction in any medium, provided the original author(s) and the source are credited.

\section{References}

Agosti D (1992) Revision of the ant genus Myrmoteras of the Malay Archipelago (Hymenoptera: Formicidae). Rev Suisse Zool 99:405-429

Aizen MA, Morales CL, Morales JM (2008) Invasive mutualists erode native pollination webs. PLoS Biol 6:e31

Aslan CE, Zavaleta ES, Tershy B, Croll D (2013) Mutualism disruption threatens global plant biodiversity: a systematic review. PLoS ONE 8:e66993
Beaulieu F, Walter DE, Proctor HC, Kitching RL (2010) The canopy starts at $0.5 \mathrm{~m}$ : predatory mites (Acari: Mesostigmata) differ between rain forest floor soil and suspended soil at any height. Biotropica 42:704-709

Bolton B (1977) The ant tribe Tetramoriini (Hymenoptera: Formicinae). The genus Tetramorium Mayr in the Oriental and Indo-Australian regions and in Australia. Bull Br Mus (Nat Hist) Entomol Ser 36:68-151

Bronstein JL, Alarcón R, Geber M (2006) The evolution of plantinsect mutualisms. New Phytol 172:412-428

Brouat C, Garcia N, Andary C, McKey D (2001) Plant lock and ant key: pairwise coevolution of an exclusion filter in an ant-plant mutualism. Proc R Soc Lond Ser B Biol Sci 268:2131-2141

Bruna EM, Lapola DM, Vasconcelos HL (2004) Interspecific variation in the defensive responses of obligate plant-ants: experimental tests and consequences for herbivory. Oecologia 138:558-565

Bruna EM, Vasconcelos HL, Heredia S (2005) The effect of habitat fragmentation on communities of mutualists: Amazonian ants and their host plants. Biol Conserv 124:209-216

Colwell RK (2009) EstimateS: statistical estimation of species richness and shared species from samples. Version 7.52. User's guide and application published online. Available at: http://viceroy.eeb. uconn.edu/estimates

Cribari-Neto F, Zeileis A (2010) Beta regression in R. J Stat Softw 34:2

Davis MA, Chew MK, Hobbs RJ, Lugo AE, Ewel JJ, Vermeij GJ, Brown JH, Rosenzweig ML, Gardener MR, Carroll SP, Thompson K, Pickett STA, Stromberg JC, Tredici PD, Suding KN, Ehrenfeld JG, Philip Grime J, Mascaro J, Briggs JC (2011) Don't judge species on their origins. Nature 474:153-154

Edwards DP, Hassall M, Sutherland WJ, Yu DW (2006) Selection for protection in an ant-plant mutualism: host sanctions, host modularity, and the principal-agent game. Proc R Soc B Biol Sci 273:595-602

Edwards D, Magrach A, Woodcock P, Yinqiu J, Lim N, Edwards F, Larsen T, Hsu W, Benedick S, Chey V, Chung A, Reynolds G, Fisher B, Laurance W, Wilcove D, Hamer K, Yu D (2014a) Selective-logging and oil palm: multi-taxon impacts, biodiversity indicators, and trade-offs for conservation planning. Ecol Appl 24:2029-2049

Edwards DP, Tobias JA, Sheil D, Meijaard E, Laurance WF (2014b) Maintaining ecosystem function and services in logged tropical forests. Trends Ecol Evol 29:511-520

Ewers RM, Banks-Leite C (2013) Fragmentation impairs the microclimate buffering effect of tropical forests. PLoS ONE 8:e58093

Fayle TM, Chung AY, Dumbrell AJ, Eggleton P, Foster WA (2009) The effect of rain forest canopy architecture on the distribution of epiphytic ferns (Asplenium spp.) in Sabah, Malaysia. Biotropica 41:676-681

Fayle TM, Turner EC, Snaddon JL, Chey VK, Chung AWC, Eggleton P, Foster WA (2010) Oil palm expansion into rain forest greatly reduces ant biodiversity in canopy, epiphytes and leaf-litter. Basic Appl Ecol 11:337-345

Fayle TM, Edwards DP, Turner EC, Dumbrell AJ, Eggleton P, Foster WA (2012) Public goods, public services, and by-product mutualism in an ant-fern symbiosis. Oikos 121:1279-1286

Fayle TM, Turner EC, Foster WA (2013) Ant mosaics occur in SE Asian oil palm plantation but not rain forest and are influenced by the presence of nest-sites and non-native species. Ecography 36:1051-1057

Fayle TM, Yusah KM, Hashimoto Y (2014) Key to the ant genera of Borneo in English and Malay. Available at: http://www.tomfayle. com/Ant\%20key.htm

Fisher B, Edwards DP, Larsen TG, Ansell FA, Hsu WW, Roberts CS, Wilcove DS (2011) Cost-effective conservation: calculating biodiversity and logging trade-offs in Southeast Asia. Conserv Lett 4:443-450 
Foster KR, Wenseleers T (2006) A general model for the evolution of mutualisms. J Evol Biol 19:1283-1293

Foster WA, Snaddon JL, Turner EC, Fayle TM, Cockerill TD, Ellwood MDF, Broad GR, Chung AYC, Eggleton P, Khen CV, Yusah KM (2011) Establishing the evidence base for maintaining biodiversity and ecosystem function in the oil palm landscapes of South East Asia. Philos Trans R Soc B Biol Sci 366:3277-3291

Gibson L, Lee TM, Lian Pin Koh, Brook BW, Gardner TA, Barlow J, Peres CA, Bradshaw CJA, Laurance WF, Lovejoy TE, Sodhi NS (2011) Primary forests are irreplaceable for sustaining tropical biodiversity. Nature 478:378-381

Hansen MC, Potapov PV, Moore R, Hancher M, Turubanova SA, Tyukavina A, Thau D, Stehman SV, Goetz SJ, Loveland TR, Kommareddy A, Egorov A, Chini L, Justice CO, Townshend JRG (2013) High-resolution global maps of 21st-century forest cover change. Science 342:850-853

Hobbs RJ, Higgs E, Harris JA (2009) Novel ecosystems: implications for conservation and restoration. Trends Ecol Evol 24:599-605

Hothorn T, Hornik K, van de Wiel M, Zeileis A (2008) Implementing a class of permutation tests: the coin package. J Stat Softw 28(8):1-23

Kiers TE, Palmer TM, Ives AR, Bruno JF, Bronstein JL (2010) Mutualisms in a changing world: an evolutionary perspective. Ecol Lett 13:1459-1474

Koh LP, Wilcove DS (2008) Is oil palm agriculture really destroying tropical biodiversity? Conserv Lett 1:60-64

Koh LP, Dunn RR, Sodhi NS, Colwell RK, Proctor HC, Smith VS (2004) Species coextinctions and the biodiversity crisis. Science 305:1632-1634

Kohout R (2006) Review of Polyrhachis (Cyrtomyrma) Forel (Hymenoptera: Formicidae: Formicinae) of Australia, Borneo, New Guinea and the Solomon Islands with descriptions of new species. Mem Qld Mus 52:87

Leimar O, Connor RC (2003) By-product benefits, reciprocity and pseudoreciprocity in mutualism. In: Hammerstein P (ed) Genetic and cultural evolution of cooperation. MIT Press, Cambridge, pp 203-222

Mack RN, Simberloff D, Lonsdale WM, Evans H, Clout M, Bazzaz FA (2000) Biotic invasions: causes, epidemiology, global consequences, and control. Ecol Appl 10:689-710

Melo FPL, Arroyo-Rodríguez V, Fahrig L, Martínez-Ramos M, Tabarelli M (2013) On the hope for biodiversity-friendly tropical landscapes. Trends Ecol Evol 28:462-468

Myers N (2000) Biodiversity hotspots for conservation priorities. Nature 403:853-858

Ness JH, Bronstein JL (2004) The effects of invasive ants on prospective ant mutualists. Biol Invasions 6:445-461

Passmore HA, Bruna EM, Heredia SM, Vasconcelos HL (2012) Resilient networks of ant-plant mutualists in Amazonian forest fragments. PLoS ONE 7:e40803

Pfeiffer M (2013) Antbase: a taxonomic ant picturebase of Asia and Europe. Available at: http://www.antbase.net/. Retrieved June 2013

Pfeiffer M, Tuck HC, Lay TC (2008) Exploring arboreal ant community composition and co-occurrence patterns in plantations of oil palm Elaeis guineensis in Borneo and Peninsular Malaysia. Ecography 31:21-32

Potts SG, Biesmeijer JC, Kremen C, Neumann P, Schweiger O, Kunin WE (2010) Global pollinator declines: trends, impacts and drivers. Trends Ecol Evol 25:345-353

Ritchie EG, Johnson CN (2009) Predator interactions, mesopredator release and biodiversity conservation. Ecol Lett 12:982-998

Scheffers BR, Phillips BL, Laurance WF, Sodhi NS, Diesmos A, Williams SE (2013) Increasing arboreality with altitude: a novel biogeographic dimension. Proc R Soc B Biol Sci 280. doi:10.1098/ rspb.2013.1581

Scheffers BR, Phillips BL, Shoo LP (2014) Asplenium bird's nest ferns in rainforest canopies are climate-contingent refuges for frogs. Glob Ecol Conserv 2:37-46

Shattuck SO (2008) Revision of the ant genus Prionopelta (Hymenoptera: Formicidae) in the Indo-Pacific region. Zootaxa 1846:21-34

Sokal RR, Rohlf JF (1995) Biometry. W. H Freeman and Company, New York

Stasinopoulos DM, Rigby RA (2007) Generalized additive models for location scale and shape (GAMLSS) in R. J Stat Softw 23:1-46

Tilman D, Fargione J, Wolff B, D'Antonio C, Dobson A, Howarth R, Schindler D, Schlesinger WH, Simberloff D, Swackhamer D (2001) Forecasting agriculturally driven global environmental change. Science 292:281-284

Traveset A, Richardson DM (2006) Biological invasions as disruptors of plant reproductive mutualisms. Trends Ecol Evol 21:208-216

Turner EC, Foster WA (2006) Assessing the influence of Bird's nest ferns (Asplenium spp.) on the local microclimate across a range of habitat disturbances in Sabah, Malaysia. Selbyana 27:195-200

Turner EC, Foster WA (2009) The impact of forest conversion to oil palm on arthropod abundance and biomass in Sabah, Malaysia. J Trop Ecol 25:23-30

Tvardikova K, Novotny V (2012) Predation on exposed and leaf-rolling artificial caterpillars in tropical forests of Papua New Guinea. J Trop Ecol 28:331-341

Tylianakis JM, Laliberté E, Nielsen A, Bascompte J (2010) Conservation of species interaction networks. Biol Conserv 143:2270-2279

Walsh RPD, Newbery DM (1999) The ecoclimatology of Danum, Sabah, in the context of the world's rainforest regions, with particular reference to dry periods and their impact. Phil Trans Biol Sci 354:1868-1883

Wang M (2003) A monographic revision of the ant genus Pristomyrmex (Hymenoptera: Formicidae). Bull Mus Comp Zool 157:383-539

Wetterer JK (1997) Ants on Cecropia in Hawaii. Biotropica 29:128-132

Weyl EG, Frederickson ME, Yu DW, Pierce NE (2010) Economic contract theory tests models of mutualism. Proc Natl Acad Sci 107:15712-15716

Wielgoss A, Tscharntke T, Rumede A, Fiala B, Seidel H, Shahabuddin S, Clough Y (2014) Interaction complexity matters: disentangling services and disservices of ant communities driving yield in tropical agroecosystems. Proc R Soc B Biol Sci 281:20132144 